Anđelka Milosavljević

Mašinski fakultet, Beograd

Milesa Srećković

Elektrotehnički fakultet, Beograd

Miomir Korać

Arheološki institut Beograd

Sanja Petronić,

Mašinski fakultet, Beograd

902.6:[621.375.826:531.715

902.6:620.1

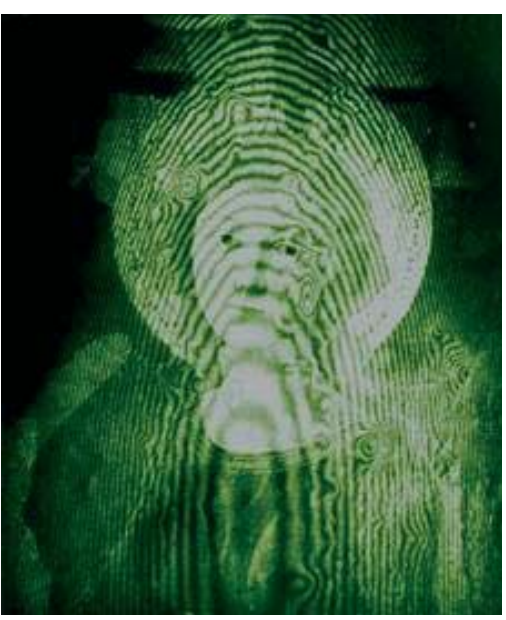

\title{
PRIMENA HOLOGRAFSKE INTERFEROMETRIJE I SKENIRAJUĆE ELEKTRONSKE MIKROSKOPIJE U ISPITIVANJU MATERIJALA PREDMETA KULTURNE BAŠTINE
}

\begin{abstract}
ABSTRAKT
U ovom radu su analizirani rezultati dobijeni holografskim interfereometrijskim istraživanjima koja su izvedena na višekomponentnim legurama aluminijuma, od kojih su izrađeni konstruktivni delovi optimalnih mehaničkih osobina. Dobijeni interferogrami svedoče o prisustvu defekata u materijalu a linearnom interpolacijom određeni su koeficijenti interferencijskih pruga. Ovo istraživanje daje sve preduslove za planiranje postupka restauracije unikatnih predmeta. Značaj primenjene skenirajuće elektronske mikroskopije ukazuje na mogućnosti otkrivanja grešaka u materijalu, kao što je snimljeno u superleguri nikla - Hastelloy S, kao i identifikacija žilavog interkristalnog loma.

Primena holografske interferometrije i skenirajuće elektronske mikroskopije je važna i za istraživanja predmeta kulturne baštine, o čemu svedoče rezultati dobijeni u najsavremenijim laboratorijama.
\end{abstract}

KLJUČNE REČI: HOLOGRAFSKA INTERFEROMETRIJA, SKENIRAJUĆA ELEKTRONSKA MIKROSKOPIJA, ARHEOLOGIJA, PREDMETI KULTURNE BAŠTINE.

Specifični problemi degradacije materijala predmeta kulturne baštine zahtevaju različite pristupe u izboru metoda ispitivanja. Izbor supstitucionog kapaciteta srodne grupe metoda vrlo je bitan za identifikovanje suštine problema, kao i za dobijanje neophodnih rezultata koji ukazuju na adekvatan način saniranja oštećenja predmeta kulturne baštine.

Kada je reč o primeni savremenih metoda ispitivanja uzoraka, holografska interferometrija i skenirajuća elektronska mikroskopija (SEM) zauzimaju posebno mesto u ispitivanju predmeta kulturne baštine. Na osnovu razmatranja novijih literaturnih podataka ${ }^{1}$ koji se odnose na različite materijale ${ }^{2}$ i savremene optičke metode ustanovljeno je da holografska interferometrija ima mogućnost za dobijanje kvalitativne slike na velikoj udaljenosti od predmeta i daje veliku tačnost

1. Milosavljević, 1997.; Milosavljević i dr. 2006

2. Milosavljević i dr. 2006; Počuča 2005 


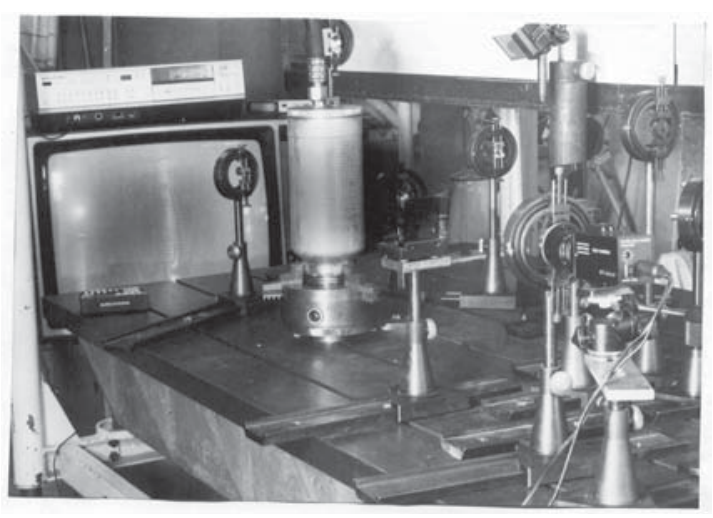

Slika 1. Holografski sistem UIG-2M

u identifikovanju defekta u materijalu.

Primena skenirajuće elektronske mikroskopije predstavlja metodu koja ne zahteva posebnu pripremu. Fokusirani snop brzih elektrona skenira površinu uzorka postupno prelazeći iz tačke u tačku. Debljina uzorka nije od značaja jer se dobija uvećani lik površine koja se skenira. Površina mora biti elektroprovodna jer u protivnom nije moguće dobiti jasan lik. Ako ispitujemo površinu metala nije potrebna dorada uzorka. Ako se ispituju neprovodni uzorci kao što su plastika, keramika, tvrda organska tkiva i drugi biološki preparati, uzorci se prethodno moraju metalizirati po površini koja će biti izložena skeniranju. Rend- gensko zračenje koje takođe nastaje pod uticajem skenirajućeg snopa X zračenja, može da odredi i atomsku strukturu uzorka. Zato svaki skenirajući elektronski mikroskop može da se koristiti da daje uvećani lik površine uzorka ili da daje energetski spektar karakterističnog X zračenja.

\section{REZULTATI ISPITIVANJA}

Ispitivanje je izvršeno u Institutu ' $\mathrm{E}$. O. Paton" u Kijevu (Ukrajina) na holografskom sistemu UIG-2M, uz primenu lasera tipa LGN-222 (sl. 1). Rezultati ispitivanja modela, izrađenog od višekomponentne legure $\mathrm{Al}-\mathrm{Zn}-\mathrm{Mg}-\mathrm{Cu}$, su dobijanje holografskih zapisa, vektora apsolutnog redosleda interferentnih pruga i komponenata vektora pomeraja. $^{1}$

Holografski je ispitivan model sa prslinom i bez prsline. Hemijskisastav ispitivane višekomponentne legure aluminijuma Al-Zn-Mg-Cu dat je u Tabeli 1. Rezultati napona na granici tečenja $\mathrm{R}_{\mathrm{p} 0,2}$, zatezne

1. Radovanović, 1999; Schumann, Zurcher, Cuche 1985.; Milosavljević i dr. 1996; Srećković i dr. 2003; Milosavljević i dr. 1996

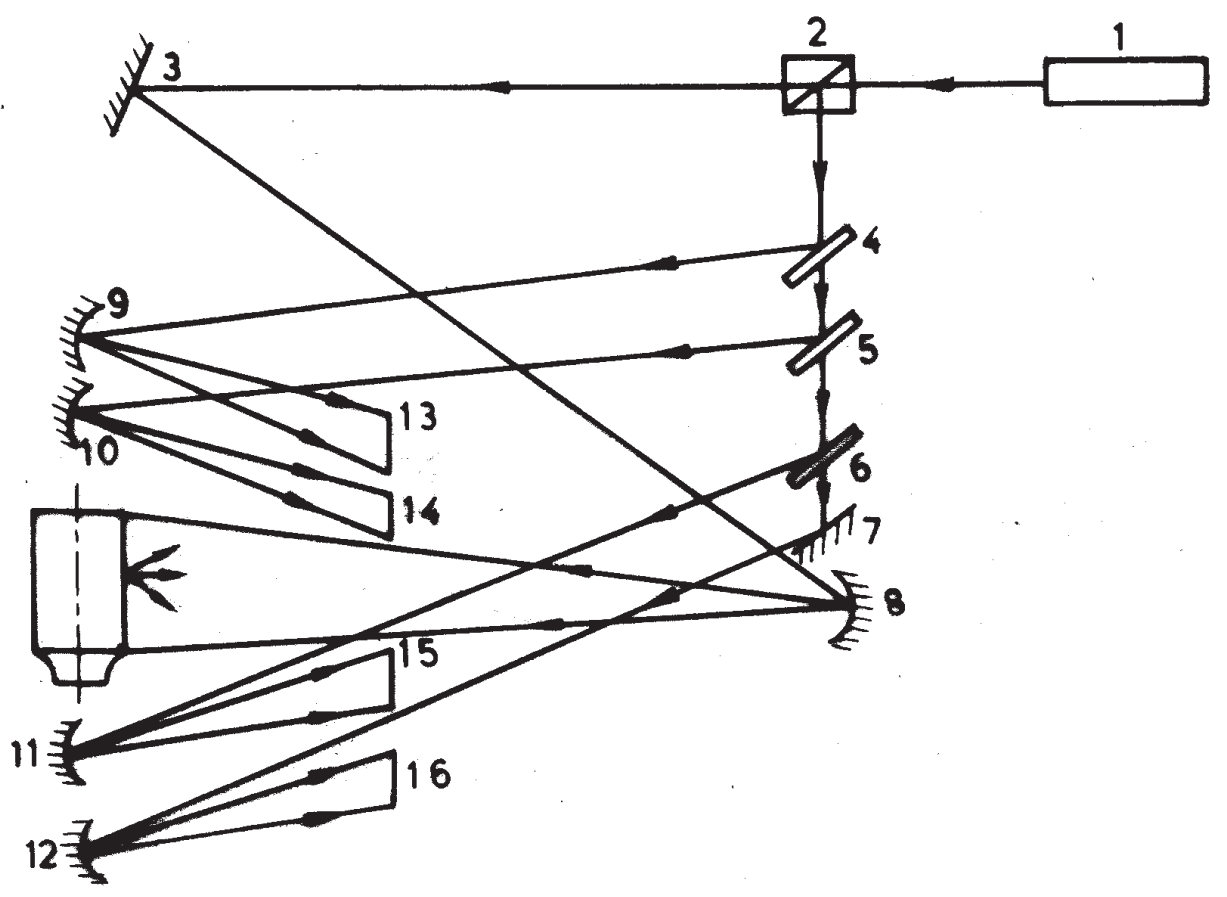

Slika 2. Optička shema ispitivanja polja pomeraja 
Tabela 1. Hemijski sastav legure Al-Zn-Mg-Cu

\begin{tabular}{|c|c|c|c|c|c|c|c|c|}
\hline Mas.\% & $\mathrm{Al}$ & $\mathrm{Zn}$ & $\mathrm{Mg}$ & $\mathrm{Cu}$ & $\mathrm{Cr}$ & $\mathrm{Mn}$ & $\mathrm{Zr}$ & Primese \\
\hline $\begin{array}{c}\text { Al-Zn-Mg- } \\
\mathrm{Cu}\end{array}$ & 88,02 & 7,20 & 2,15 & 1,46 & 0,60 & 0,28 & 0,12 & $\begin{array}{c}\mathrm{Fe}-0,12 \\
\mathrm{Si}-0,05\end{array}$ \\
\hline
\end{tabular}
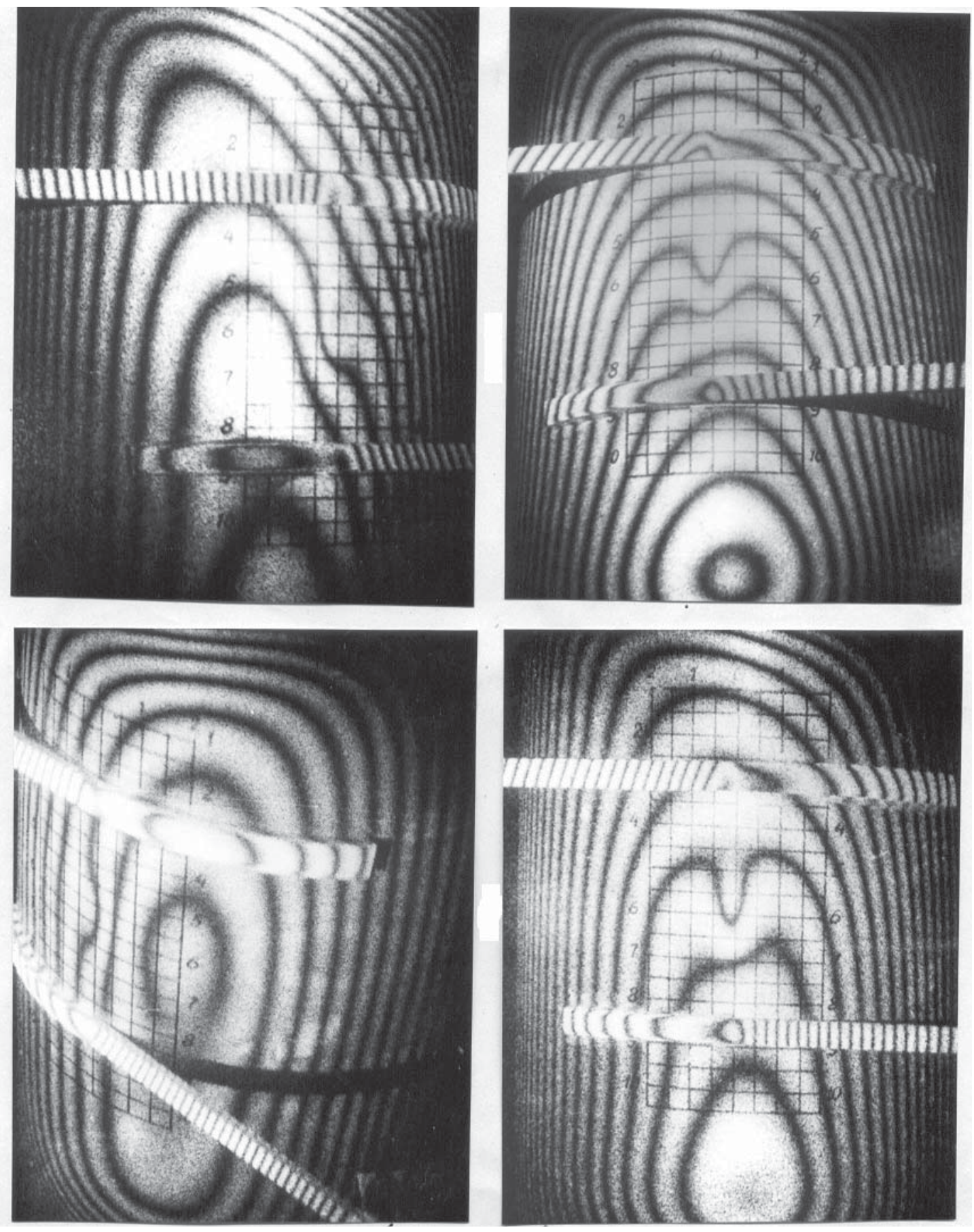

Slika 3. interferogrami dobijeni pri pritisku 1,0 MPa : za deo površine modela bez defekta (a), za deo površine sa prslinom dužine $22 \mathrm{~mm}$ (b), za deo površine sa prslinom dužine $100 \mathrm{~mm}$ (c), sa mesta posmatranja $\mathrm{H} 1$ 
čvrstoće $\mathrm{R}_{\mathrm{M}}$, procentualnog izduženja A (\%) i tvrdoće po Brinelu dati su u Tabeli 2.

Komora visokog pritiska data je na slici 2, pod brojem 17. Na modelu, koji je preko glave podeonog aparata, učvršćen za postolje uređaja za snimanje, nanosi se u odgovarajućem koordinatnom sistemu mreža $5 \times 5 \mathrm{~mm}$, pomoću koje se vrši posmatranje tačaka čiju deformaciju, odnosno pomeraje treba da odredimo.

$\mathrm{Na}$ osnovu usvojenog pritiska za određeno stanje modela, definisanog interferometra, odnosno optičke šeme, pristupilo se dobijanju interferograma, kako opterećenog modela, tako i bez dejstva unutrašnjeg pritiska (sl. 3).

Na slici 2 data je optička šema ispitivanja polja pomeraja modela sa prslinom, pod dejstvom unutrašnjeg pritiska. U optičkoj šemi je interferometar za snimanje četiri holograma. Četvrti hologram služi za jednoznačno dobijanje sistema jednačina: 1 - laser; 2 - prizma za razdvajanje laserskog snopa; 3, 7- ravna ogledala; 4, 5, 6 - polupropustljiva ogledala; $8,9,10,11,12$ - sferna ogledala; 13, 14, 15, 16 - holografske ploče; 17 - ispitivani model (cilindrični omotač).
Za usvojeni koordinantni sistem i oblik modela unapred je poznat znak komponente $w$, tj. znak pomeraja u pravcu $z$-ose. Zbog toga su parametri izabrani tako da osetljivost pri snimanju holograma $\mathrm{H}_{4}$ bude maksimalna prema komponenti $w$, odnosno postavljen je što je moguće bliže osi izvora osvetljenja (Tabela 3).

Laserski snop se iz laserskog izvora svetlosti 1 , pomoću prizme za razdvajanje snopa 2 , deli na dva - objektni i referentni. Objektni snop, odbivši se od ravnog ogledala 3, pada na sferno ogledalo 8 , koje služi za širenje laserskog snopa. Prošireni objektni snop pada na površinu cilindričnog omotača 17 i difuzno reflektuje, pogađajući površine holografskih ploča 13, 14, 15 i 16. Drugi snop, izašavši iz delitelja 2 , dospeva na polupropustljiva ogledala 4, 5, 6 i 7, a zatim se širi sfernim ogledalima 9, 10, 11 i 12 i tako postaje referentan za dobijanje holograma $\mathrm{H}_{1}, \mathrm{H}_{2}, \mathrm{H}_{3} \mathrm{i} \mathrm{H}_{4}$

$\mathrm{U}$ odnosu na usvojeni koordinatni sistem laserski izvor svetlosti 1 ima koordinate $x_{0}=0, y_{0}=$ $0, z_{0}=830 \mathrm{~mm}$.

Linearnom interpolacijom određeni su koeficijenti redosleda interferencijskih pruga $K_{l}, K_{2}$,

Tabela 2. Mehaničke osobine legure $\mathrm{Al}-\mathrm{Zn}-\mathrm{Mg}-\mathrm{Cu}$ posle termomehaničkih obrada

\begin{tabular}{|c|c|c|c|c|}
\hline $\mathrm{Q}+\mathrm{W}+\mathrm{T}_{2}$ & $\mathrm{R}_{\mathrm{p} 02}(\mathrm{MPa})$ & $\mathrm{R}_{\mathrm{M}}(\mathrm{MPa})$ & $\mathrm{A}(\%)$ & $\mathrm{HB}$ \\
\hline $\mathrm{Q}+20 \%+30 \mathrm{~min} . / 190^{\circ} \mathrm{C}$ & 645 & 670 & 8,7 & 200 \\
\hline
\end{tabular}

Tabela 3. Koordinate holograma

\begin{tabular}{|c|c|c|c|}
\hline Hologram & \multicolumn{3}{|c|}{ Koordinata $(\mathrm{mm})$} \\
\hline $\mathrm{H}_{\mathrm{i}}$ & $x_{i}$ & $y_{i}$ & $z_{i}$ \\
\hline $\mathrm{H}_{1}$ & $-151,20$ & 75,60 & 362,50 \\
\hline $\mathrm{H}_{2}$ & 75,60 & $-151,20$ & 362,50 \\
\hline $\mathrm{H}_{3}$ & 181,00 & 181,00 & 156,00 \\
\hline $\mathrm{H}_{4}$ & 0,00 & 0,00 & 455,00 \\
\hline
\end{tabular}

Tabela 4. Pritisci ispitivanja i stanje modela

\begin{tabular}{|c|c|}
\hline Pritisak $p(\mathrm{MPa})$ & Stanje modela \\
\hline 0,5 & bez defekta \\
\hline 1,0 & bez defekta \\
\hline 0,5 & dužina prsline $l=100 \mathrm{~mm}$ \\
\hline 1,0 & dužina prsline $l=100 \mathrm{~mm}$ \\
\hline
\end{tabular}


Tabela 5. Vrednosti koeficijenta redosleda interferencijskih pruga $K_{1}$

\begin{tabular}{|c|c|c|c|c|}
\hline \multirow{2}{*}{$X_{j}$} & \multirow{2}{*}{$Y$} & \multicolumn{3}{|c|}{$K_{l}$} \\
\hline & & $x=-2,5 \mathrm{~mm}$ & $x=0$ & $x=+2,5 \mathrm{~mm}$ \\
\hline \multirow[t]{2}{*}{1} & -45 & 14,4 & 14,0 & 13,5 \\
\hline & -40 & 14,4 & 14,15 & 14,05 \\
\hline \multirow{2}{*}{2} & -35 & 14,45 & 14,3 & 14,5 \\
\hline & -30 & 14,5 & 14,5 & 14,0 \\
\hline \multirow{2}{*}{3} & -25 & 14,15 & 13,5 & 13,6 \\
\hline & -20 & 13,4 & 12,6 & 13,15 \\
\hline \multirow{2}{*}{4} & -15 & 12,9 & 12,1 & 12,6 \\
\hline & -10 & 12,5 & 11,6 & 12,35 \\
\hline \multirow{2}{*}{5} & -5 & 12,5 & 11,35 & 12,1 \\
\hline & 0 & 12,5 & 11,15 & 11,9 \\
\hline \multirow{2}{*}{6} & +5 & 12,5 & 11,05 & 11,75 \\
\hline & +10 & 12,5 & 11,25 & 12,0 \\
\hline \multirow{2}{*}{7} & 15 & 12,5 & 11,45 & 12,9 \\
\hline & 20 & 12,65 & 11,8 & 12,4 \\
\hline \multirow{2}{*}{8} & 25 & 13,05 & 12,15 & 12,7 \\
\hline & 30 & 13,4 & 12,5 & 13,15 \\
\hline \multirow{2}{*}{9} & 35 & 13,95 & 13,0 & 13,55 \\
\hline & 40 & 14,6 & 13,6 & 14,2 \\
\hline \multirow{2}{*}{10} & 45 & 15,65 & 14,4 & 14,95 \\
\hline & 50 & 16,35 & 15,15 & 15,65 \\
\hline \multirow{2}{*}{11} & 55 & 17,3 & 16,0 & 16,4 \\
\hline & 60 & 18,2 & 16,95 & 17,4 \\
\hline \multirow{2}{*}{12} & 65 & 19,4 & 18,3 & 18,8 \\
\hline & 70 & 20,85 & 20,0 & 20,25 \\
\hline \multirow{2}{*}{13} & 75 & 22,6 & 22,1 & 21,8 \\
\hline & 80 & 24,1 & 23,6 & 23,15 \\
\hline
\end{tabular}


Tabela 6. Vrednosti koeficijenta redosleda interferencijskih pruga $K_{2}$

\begin{tabular}{|c|c|c|c|c|}
\hline \multirow{2}{*}{$X_{j}$} & \multirow{2}{*}{$Y$} & \multicolumn{3}{|c|}{$K_{2}$} \\
\hline & & $x=-2,5 \mathrm{~mm}$ & $x=0$ & $x=+2,5 \mathrm{~mm}$ \\
\hline \multirow[t]{2}{*}{1} & -45 & 7,0 & 7,0 & 7,0 \\
\hline & -40 & 7,65 & 7,65 & 7,65 \\
\hline \multirow{2}{*}{2} & -35 & 7,95 & 8,0 & 8,0 \\
\hline & -30 & 7,75 & 7,6 & 7,7 \\
\hline \multirow{2}{*}{3} & -25 & 7,5 & 6,9 & 7,3 \\
\hline & -20 & 6,5 & 5,85 & 6,6 \\
\hline \multirow{2}{*}{4} & -15 & 6,05 & 5,3 & 6,1 \\
\hline & -10 & 5,65 & 4,9 & 5,65 \\
\hline \multirow{2}{*}{5} & -5 & 5,5 & 4,5 & 5,5 \\
\hline & 0 & 5,5 & 4,2 & 5,5 \\
\hline \multirow{2}{*}{6} & +5 & 5,5 & 4,3 & 5,5 \\
\hline & +10 & 5,5 & 4,6 & 5,5 \\
\hline \multirow{2}{*}{7} & 15 & 5,85 & 4,9 & 5,75 \\
\hline & 20 & 6,25 & 5,15 & 6,1 \\
\hline \multirow{2}{*}{8} & 25 & 6,65 & 5,45 & 6,45 \\
\hline & 30 & 7,15 & 6,0 & 6,95 \\
\hline \multirow{2}{*}{9} & 35 & 7,7 & 6,6 & 7,5 \\
\hline & 40 & 8,65 & 7,4 & 8,25 \\
\hline \multirow{2}{*}{10} & 45 & 9,5 & 8,35 & 9,15 \\
\hline & 50 & 10,5 & 9,2 & 9,95 \\
\hline \multirow{2}{*}{11} & 55 & 11,3 & 10,15 & 10,9 \\
\hline & 60 & 12,35 & 11,25 & 12,0 \\
\hline \multirow{2}{*}{12} & 65 & 13,8 & 12,5 & 13,3 \\
\hline & 70 & 15,5 & 14,3 & 14,9 \\
\hline \multirow{2}{*}{13} & 75 & 17,45 & 16,8 & 16,7 \\
\hline & 80 & 19,05 & 18,5 & 18,3 \\
\hline
\end{tabular}


Tabela 7. Vrednosti koeficijenata redosleda interferencijskih pruga $K_{3}$ i $K_{4}$

\begin{tabular}{|c|c|c|c|c|c|}
\hline \multirow{2}{*}{$X_{j}$} & \multirow{2}{*}{ Y } & \multicolumn{3}{|c|}{$K_{3}$} & \multirow{2}{*}{$\frac{K_{d}}{x=0}$} \\
\hline & & $x=-2,5 \mathrm{~mm}$ & $x=0$ & $x=+2,5 \mathrm{~mm}$ & \\
\hline \multirow{2}{*}{1} & -45 & & & & \\
\hline & -40 & & & & \\
\hline \multirow{2}{*}{2} & -35 & 32,4 & 32,2 & 32,4 & 18,95 \\
\hline & -30 & 34,65 & 31,1 & 31,45 & 18,50 \\
\hline \multirow{2}{*}{3} & -25 & 30,3 & 30,0 & 30,5 & 16,80 \\
\hline & -20 & 29,5 & 29,0 & 29,8 & 16,80 \\
\hline \multirow{2}{*}{4} & -15 & 29,15 & 28,35 & 29,3 & 15,60 \\
\hline & -10 & 28,8 & 27,9 & 28,85 & 15,10 \\
\hline \multirow{2}{*}{5} & -5 & 28,5 & 27,5 & 28,5 & 14,70 \\
\hline & 0 & 28,35 & 27,3 & 28,2 & 14,35 \\
\hline \multirow{2}{*}{6} & +5 & 28,15 & 27,15 & 27,9 & 14,10 \\
\hline & +10 & 28,0 & 27,0 & 27,65 & 14,10 \\
\hline \multirow{2}{*}{7} & 15 & 28,15 & 27,15 & 27,65 & 14,10 \\
\hline & 20 & 28,3 & 27,25 & 27,65 & 14,40 \\
\hline \multirow{2}{*}{8} & 25 & 28,45 & 27,4 & 28,15 & 15,05 \\
\hline & 30 & 28,8 & 27,6 & 28,4 & 15,40 \\
\hline \multirow{2}{*}{9} & 35 & 29,15 & 27,95 & 28,75 & 15,90 \\
\hline & 40 & 29,6 & 28,3 & 29,15 & 16,50 \\
\hline \multirow{2}{*}{10} & 45 & 30,1 & 28,8 & 29,55 & 17,35 \\
\hline & 50 & 30,5 & 29,35 & 30,1 & 18,00 \\
\hline \multirow{2}{*}{11} & 55 & 31,05 & 30,05 & 30,65 & 18,90 \\
\hline & 60 & 31,7 & 30,75 & 31,3 & 19,95 \\
\hline \multirow{2}{*}{12} & 65 & 32,7 & 31,5 & 32,2 & 21,00 \\
\hline & 70 & 33,5 & 32,8 & 33,3 & 22,90 \\
\hline \multirow{2}{*}{13} & 75 & 34,6 & 34,6 & 34,6 & 25,10 \\
\hline & 80 & 35,75 & 35,85 & 35,75 & 26,50 \\
\hline
\end{tabular}

$K_{3}$ i $K_{4}$, za model sa prslinom $l=100 \mathrm{~mm}$ i pri unutrašnjem pritisku komore - modela $p=0,5-1,0$ MPa, čije su vrednosti date u Tabelama 4, 5, 6 i 7.

Takođe optička metoda holografske interferometrije primenjiva je na unikatnim predmetima. $\mathrm{Na}$ slici 4. prikazan je interferogram ikone Svete Katarine, a na slici 5. interferogram drvene skulture iz XIII veka.

Na osnovu holograma Santa Caterina (sl. 4) i holograma drvene skulputure (sl. 5) može da se kaže da je ova primenjena metoda od značaja za rekonstrukciju likova na starim umetničkim predmetima.

$\mathrm{Na}$ slici 6. data je mikrografija snimljena skenirajućim elektronskim mikroskopom koja pokazuje dominirajuće prisustvo žilavog loma, prelomne površine epruvete izrađene od superlegure nikla Hastelloy S. Ispitivanja super legura nikla tipa Hastelloy S, Hasteloy X su značajna zato što ove višekomponentne legure imaju veliku praktičnu primenu u avioindustriji, termoenergetici, raketnoj i nuklaeranoj tehnici. Za razumevanje promena u strukturi složenih sistema novih materijala, a takođe i predmeta kulturne baštine neophodna je primena novih tehnologija.

\section{ZAKLJUČAK}

Razmatranjem podataka iz literature, ${ }^{1}$ analizom rezultata dobijenih procesiranjem holograma dobijenih na osnovu ispitivanja višekomponentne

1. Schumann, Zurcher, Cuche 1985; Milosavljević i dr. 1997; Radovanović 1999, Milosavljević i dr. 2003; Srećković i dr. 2003; 
legure aluminijuma $\mathrm{Al}-\mathrm{Zn}-\mathrm{Mg}-\mathrm{Cu}$, analizom rezultata ispitivanja - SEM superlegure Hastelloy S autori rada su došli do sledećih zaključaka:

- Poređenjem dobijenih vrednosti mehaničkih karakteristika ustanovljeno je optimalno stanje legure Al-Zn-Mg-Cu: Q + $20 \%+30$ min. / 190 ${ }^{\circ} \mathrm{C}$ od koje je napravljen model za ispitivanje holografskom interferometrijom.

- Metode holografske interferometrije u analizi deformacija i napona doprinose osavremenjivanju i aktualizaciji klasičnih metoda, kao što su tenzometrija, fotoelastičnost, mreže i druge, a takođe omogućavaju analizu interferograma snimljenim na predmetima kulturne baštine. ${ }^{1}$

- Holografska interferometrija je univerzalna metoda digitalnog ocenjivanja, koja pruža značajne merne rezultate $u$ dijagnostici materijala i daje informacionu sliku visoke preciznosti. Zbog toga bi bilo korisno da bude više zastupljena u procesima ispitivanja bez razaranja i kontrole kvaliteta, kao i ispitivanjima unikatnih muzejskih $i$ arheoloških predmeta.

\section{RESUME}

\section{Applying of Holographic Interferometry and Scanning Electron Microskopy for Investigation of Cultural Haritage Objects Materials}

In this paper were analyzed results obtained by holographic interferemetric investigation carried out on multicomponent aluminum alloys, used for the fabrication of constructive parts which have the optimal mechanical properties. Obtained interferographs show the presence of defects in material, and by linear interpolation were determinated the coefficients of interference lines. This investigation gives all prerequest for restoration procedure planning of unique objects. Importance of applied scanning electron microscopy SEM points at possibilities of detecting the defects in materials, such as observed in nickel based superalloys, with the special regard to occurrence

1. Milosavljević i dr. 1996; Milosavljević i dr. 2001;

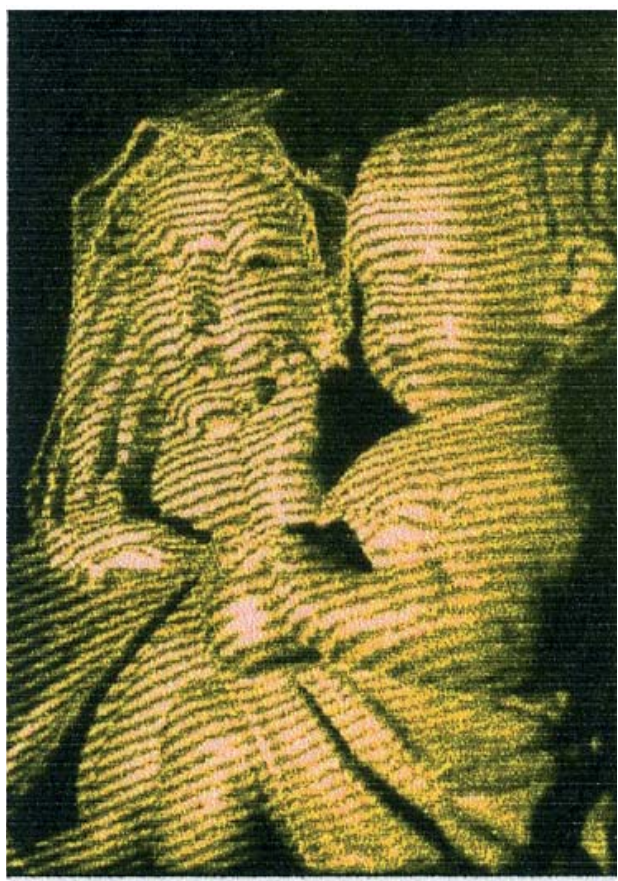

Slika 5. Interferogram drvene skulpture

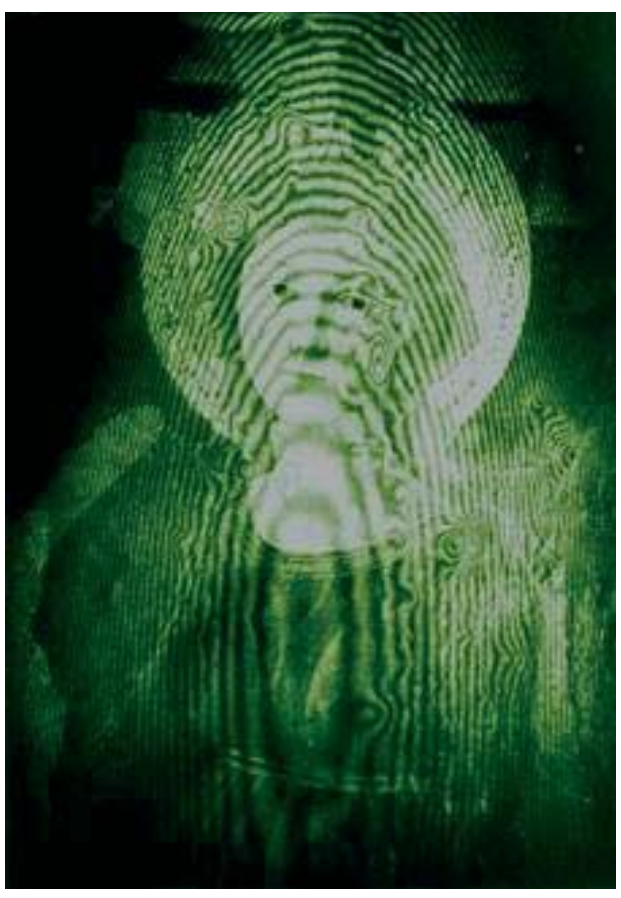

Slika 4. Interferogram "Santa Caterina" (1450) Piera Frančeska Fiorentina koji je realizovao profesor Gori sa saradnicima u Laser Laboratory 1970. 


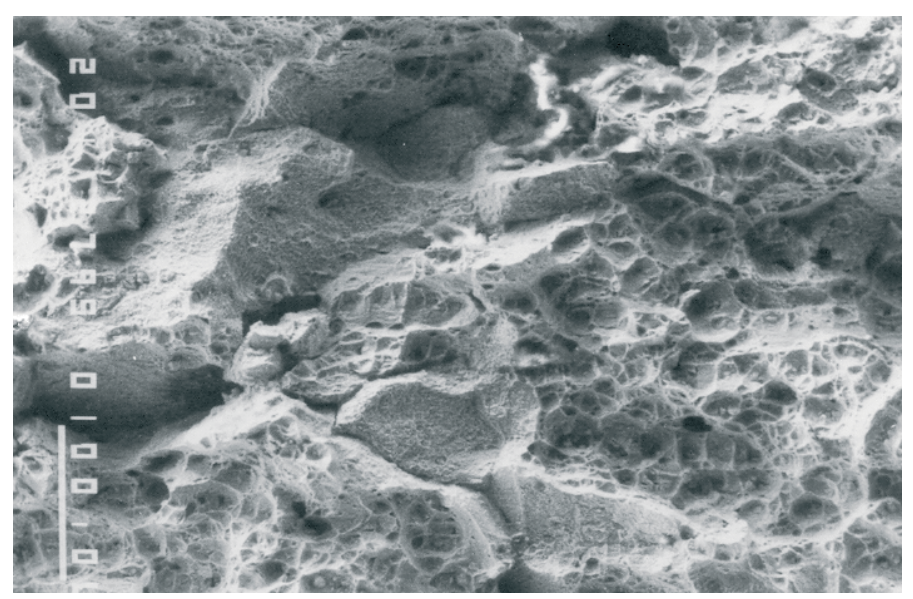

Slika 6. Mikrografija žilavog loma dobijena skenirajućim elektronskim mikroskopom. Uvećanje 200X.

of microcracks, as well as identification of brittle or ductile fracture.

Applying of these methods is important for investigation of cultural heritage objects that is supported by results obtained in the most modern laboratories.

\section{LITERATURA}

\section{Gospavić i dr. 2003}

Gospavić, R., Srećković, M., Bojanić, S., Milosavljević, A., Radovanović, R., Kovačević, A., Modeling of Laser Beam Thermal Effects on Material, International Conference "Laser Technologies in Welding and Materials Processing”, Ukraine, Crimea, Black Sea coast, Katsiveli Town, May 19-23, 2003.

\section{Milosavljević i dr. 1996}

Milosavljević, A. Srećković, M. Prokić-Cvetković, R. Ristić, S. Vereb, L. Dinulović, M. Transformer Plates and Changes in their Structure Provoked by Laser Radiation in Two Workin Regimes. Physics of Low - Dimensional Structures 4/5 (1996) pages 95-106

\section{Milosavljević i dr. 1997}

Milosavljević, A., Srećković, M. at all, Structural changes of an Al-Li-Cu-Mg alloy during thermo-mechanical and laser treatment, Aluminium, Int. Journal of Industry, Research and Application, Vol. 73, June 1997.

\section{Milosavljević i dr. 2000}

Milosavljević, A., Kovačević, K., Miladinov, M. Radovanović, R., Nešić, I., Đorđević, D., Lekić, S., Laser Beam effects on Multicomponent Aluminium Alloys. P. 198, International Conference Welding \& Joining 2000 - New Materials \& New Perspectives, Conference Abstracts and Proceedings, Tel Aviv, Israel, 18-20 July 2000.

\section{Milosavljević i dr. 2003}

Milosavljević, A. Polić-Radovanović, S. Radovanović, R., Sadejstvo tehnologije i kulture u očuvanju nacionalne baštine. Zbornik radova XI naučnog skupa “Tehnologija kultura i razvoj“ Beograd 2003: 262-269

\section{Milosavljević i dr. 2006}

Milosavljević, A., Petronić, S., Kovacević, K., Prokić-Cvetković, R., Nesić, I., Popović, O., Pljakić, R., Kutin, M.: Fine-structural investigation of nickel based superalloys after various heat treatments, novi materijali, YUCOMAT, Herceg Novi, 2006.

\section{Milovanović i dr. 2001}

Milovanović, A., Radovanović, R., Srećković, M., Polić Radovanović, S., Interferometry control in testing rocket motors and vessels under pressure, Int. Conference on LASERS 2001, December 3-7, 2001, Tucson, Arizona, USA. 
Počuča 2005

Počuča, E., Milosavljević, A., Srecković, M., Prokić-Cvetković, R., Kutin, M., Radaković, Z., Nesić, I.: Structural Changes in Ni-based superalloy as a result of Structural element Welding, Welding and Joining, Tel Aviv 2005.

\section{Radovanović 1999}

Radovanović, R., Uticaj laserskog zračenja na strukturne promene bimetala $i$ višekomponentnih legura lakih metala, magistarska teza, Mašinski fakultet, Beograd, 1999.

\section{Schumann, Zurcher, Cuche 1985}

Schumann, W., Zurcher, J. P., Cuche, D., Holography and deformation analysis, Berlin, Heidelberg, New York, Tokio: Springer - Verlag, 1985.

\section{Srećković i dr. 2003}

Srećković, M., Gospavić, R., Milosavljević, A., Radovanović, R., Kovačević, A., Modeling on Laser - Material Interaction for Limited Geometrical Structures, Unido Virtual Laser Materials Processing Forum, Crete, Greece, 2003. 